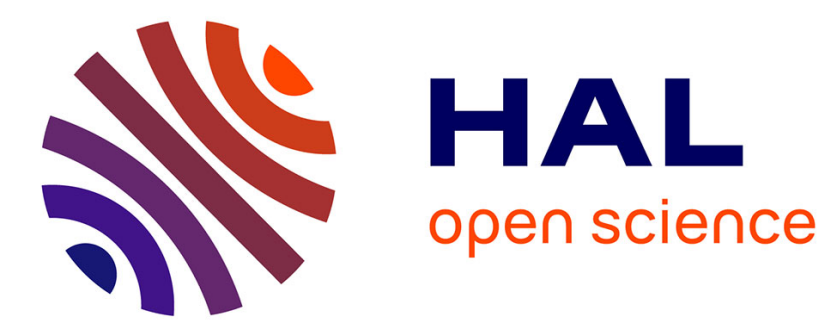

\title{
Molecular Characterization of Contaminants in Soils by Spatially Resolved XRF \& XANES Spectroscopy
}

\author{
P. Bertsch, D. Hunter, P. Nuessle, S. Clark
}

\section{To cite this version:}

P. Bertsch, D. Hunter, P. Nuessle, S. Clark. Molecular Characterization of Contaminants in Soils by Spatially Resolved XRF \& XANES Spectroscopy. Journal de Physique IV Proceedings, 1997, 7 (C2), pp.C2-817-C2-818. 10.1051/jp4:1997245 . jpa-00255324

\section{HAL Id: jpa-00255324 https://hal.science/jpa-00255324}

Submitted on 1 Jan 1997

HAL is a multi-disciplinary open access archive for the deposit and dissemination of scientific research documents, whether they are published or not. The documents may come from teaching and research institutions in France or abroad, or from public or private research centers.
L'archive ouverte pluridisciplinaire HAL, est destinée au dépôt et à la diffusion de documents scientifiques de niveau recherche, publiés ou non, émanant des établissements d'enseignement et de recherche français ou étrangers, des laboratoires publics ou privés. 


\title{
Molecular Characterization of Contaminants in Soils by Spatially Resolved XRF \& XANES Spectroscopy
}

\author{
P.M. Bertsch, D.B. Hunter, P.R. Nuessle and S.B. Clark \\ Advanced Analytical Center for Environmental Sciences/SREL, The University of Georgia, Drawer E, \\ Aiden SC 29802, U.S.A.
}

\begin{abstract}
Using a dedicated microprobe beam line (X-26A NSLS) we have conducted spatially resolved XRF and XAS studies on a variety of environmental samples and on samples produced in waste isolation and processing activities. XANES spectroscopy has provided detailed information on the oxidation states of $U$ in contaminated soils on regions as small as $50 \mu \mathrm{m}$, with minimal sample manipulation. Qualitative information on bonding environments of $U$ have been deduced based upon elemental associations generated at $10 \mu \mathrm{m}$ spatial resolution on identical regions where complete XANES spectra were collected and also on the 'fingerprint' or multiple scattering regions of the XANES spectra. Distinct regions within the sediments were found to contain phases of predominately U(VI) and U(IV). On the spatial scale examined, the U(VI) was present both as diffusely distributed and as discrete phases, whereas phases containing predominately U(IV) were present exclusively as discrete phases. Examination of a large population of individual grains prior to and following extraction with a sodium carbonate lixiviant, revealed that the U(IV) phases were highly enriched following extraction, suggesting more selective solubilization of U(VI) phases. This study illustrates the utility of combining spatially resolved XRF and XANES to evaluate chemical intervention technologies.
\end{abstract}

\section{INTRODUCTION}

A major obstacle in developing realistic environmental risk assessment or in designing environmentally sound, yet cost effective chemical and biological remediation strategies has been the inability to properly characterize the chemical speciation of contaminants in an environmental sample or wasteform. The most commonly employed methods for estimating oxidation states and solid phase associations of contaminant metals and metalloids has involved serial chemical extraction followed by assignment of the extracted fractions to operationally defined chemical forms. These indirect methods suffer from significant variabilities introduced by system specificity and also by the uncertainty surrounding chemical species transformations that may be induced during extraction. Electron micro-beam techniques have been employed in some instances where metal and metalloid speciation is evaluated by a combination of EDX analysis, EELS spectroscopy, and selected area electron diffraction. Questions surrounding sample integrity during drying and as a result of exposure to a high vacuum environment often limit the ability to extrapolate the results from these analyses to environmental scenarios. Furthermore, these techniques require relatively high contaminant concentrations due to their inherently poor sensitivity for heavier elements.

Oxidation state is a fundamental property of $U$ speciation that greatly influences its solubility and, thus, mobility. Whereas U(VI) forms soluble complexes with a number of ligands in most surface water and groundwater, U(IV) forms highly insoluble solid phases such as uraninite $(\mathrm{c})$. Chemical intervention technologies that attempt to solubilize contaminants via lixiviants or chemically stabilize them by reduction or precipitation require significant empirical testing in soils and geological materials since methods for direct molecular characterization of the contaminant before and following treatment are lacking. Two very promising techniques for providing information on the chemical speciation of a wide range of inorganic contaminants in contaminated and chemically remediated soil is synchrotron-based $\mathrm{X}$-ray absorption spectroscopy (XAS) coupled with X-ray fluorescence spectroscopy (SXRF) [1].

In past investigations, we have demonstrated the utility of these methods for providing information on $U$ oxidation states and elemental associations in contaminated soils [1]. Elemental distribution maps and XANES spectra on regions as small as $\sim 10 \mu \mathrm{m}$ are possible and have allowed for the molecular characterization of contaminant metals and metalloids heterogeneously distributed in complex samples. The objectives of this study were to employ these techniques for the molecular characterization of $U$ in samples subjected to chemical remediation strategies.

\section{RESULTS}

The synchrotron X-ray fluorescence microprobe on beamline X-26A at the National Synchrotron Light Source (Brookhaven National Laboratory, NY) was used in its normal configuration [2] with the addition of a silicon, channel-cut (111) monochromator on the incident radiation for XANES spectroscopy. The beam size was adjusted to $\sim 10 \mu \mathrm{m}$ spot size for XRF with a pinhole collimator and to between $50 \times 50$ and $300 \times 300 \mu \mathrm{m}$ for XANES with tantalum shutters operated via a computer controlled motorized stepping micrometer. XANES spectra were collected at $0.3 \mathrm{eV}$ step increments over a 120 $\mathrm{eV}$ energy range (relative to $17163 \mathrm{eV}$ for the $\mathrm{UL}_{\text {III }}$ edge) extending from about $50 \mathrm{eV}$ below to approximately $100 \mathrm{eV}$ above 
the $U L_{\text {III }}$ absorption edge. Data were collected at each incident step until $\sim 10,000$ total counts were achieved, typically for between 2 and 20 live seconds. The U L III fluorescence X-rays were measured under ambient conditions with a Si(Li) energy dispersive detector having an area of $30 \mathrm{~mm}^{2}$ mounted at 90 degrees to the incident beam and $1 \mathrm{~cm}$ from the sample. $U$ contaminated soils were collected from two U.S. Department of Energy former nuclear materials processing facilities, the Fernald Site near Cincinati, $\mathrm{OH}$, and the Savannah River Site, near Aiken, SC. Samples were size fractionated (50-300 $\mu \mathrm{m})$ and mounted on Kapton tape or, for the chemically extracted samples, embedded in a Si matrix.

Two dimensional XRF scans of $U$ contaminated samples revealed that $U$ was heterogeneously distributed within the soils and in some instances within a single grain. Examination of over 100 particles in the 50 to $300 \mu \mathrm{m}$ size range by a combination of micro-XANES, SXRF, and wet chemical methods revealed that the U could be assigned to at least two major populations. The first was diffusely distributed within the samples at relatively low $U$ concentrations and co-associated with high concentrations of elements typically found in soil (e.g., Fe, Mn, $\mathrm{Cr}$ ) (Figure la). The second population was present at locally high $\mathrm{U}$ concentrations but depleted in $\mathrm{Fe}, \mathrm{Cr}$ and other elements usually present in soil and geological samples, suggesting the presence of discrete $U$ phases (Figure $1 \mathrm{lb} \& 1 \mathrm{c}$ ).

Micro-XANES spectra collected on these particles revealed that the $U$ in the former population was predominately in the +6 oxidation state. The later population could be divided into sub-populations, one where the discrete phases were predominately $\mathrm{U}(\mathrm{VI})$ (Figure $1 \mathrm{~b}$ ) and a second where they were predominately U(IV) (Figure 1c), based both on the energy of the edge position and on the absence of diagnostic features in the multiple scattering regions of the XANES spectra that are characteristic of the uranyl [U(VI)] species. The discrete U(TV) particles were often found enriched in co-contaminant metals such as $\mathrm{Pb}$, consistent with the argument that they may have been introduced to the environment as discrete U(IV) phases rather than through secondary reduction/precipitation reactions (Figure 1c) [3]. Extraction of the soils with a Na-carbonate lixiviant revealed that the $U(V I)$ phases were efficiently solubilized for many but not all particles. Based on previous studies employing electron microprobe techniques (3) and our preliminary investigations, we hypothesize that the insoluble U(VI) phases are present as $U$ phosphates, such as meta-autunite $\left(\mathrm{Ca}\left(\mathrm{UO}_{2}\right)_{2}\left(\mathrm{PO}_{4}\right)_{2} \bullet 4 \mathrm{H}_{2} \mathrm{O}\right\}$. Additional studies are underway to confirm this assignment. Unlike the U(VI) forms, the discrete U(IV) phases were inefficiently solubilized by the Nacarbonate lixiviant and were, therefore, highly enriched following extraction. The results demonstrate the utility of spatially resolved XRF and XANES spectroscopy for evaluating chemical remediation technologies.

A
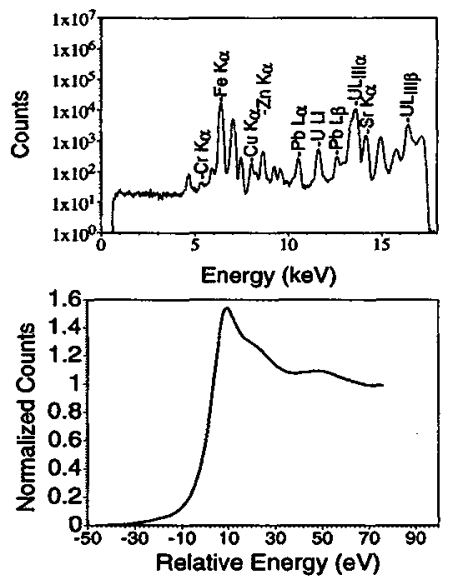

B
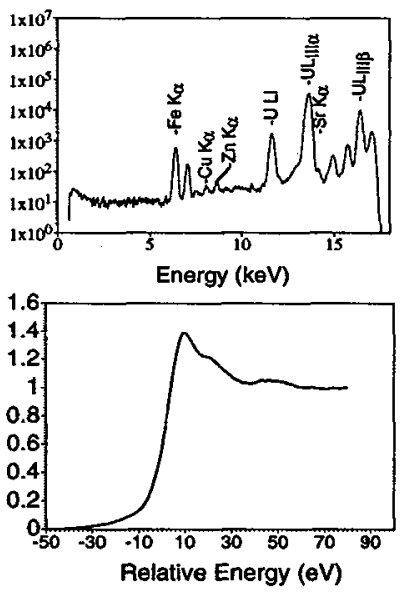

C
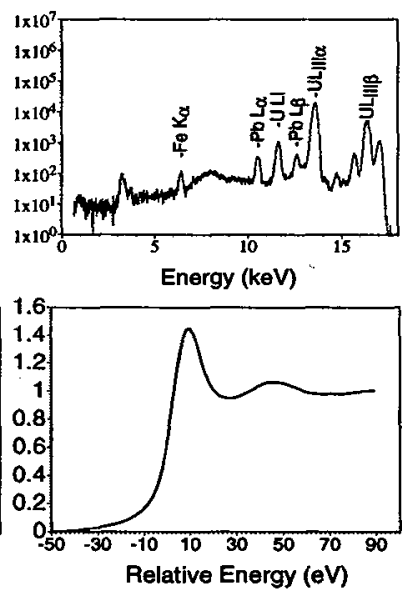

Figure 1. Examples of XRF (top) and XANES spectra (bottom) of distinct regions within the 50 to $300 \mu \mathrm{m}$ size fraction of a $U$ contaminated sample illustrating diffuse $U(A)$ and discrete $U$ (B \&C) phases (see text for details).

\section{Acknowledgments}

This work was partially funded by Financial Assistance Award Number DE-FC09-96SR18546 from the U.S. Department of Energy to the University of Georgia Research Foundation.

\section{References}

[1] Bertsch, P.M., D.B. Hunter, S.R. Sutton, S. Bajt, and M.L. Rivers. 1994. Environ. Sci. Technol. 28(5);980-984.

[2] Hanson, A.L.; Jones, K.W.; Gordon, B.M.; Pounds, J.G.; Kwiatek, W.; M.L. Rivers, M.L.; Schiklovsky, G.; Sutton, S.R. Nucl. Instrum. Methods, 1987 B24/25, 400.

[3] Buck, E.C., N.R. Brown, and N.L. Dietz. 1996. Environ. Sci. Technol. 30(1):81-88. 